\title{
Revealing the News:
}

\section{How Online News Changes Without You Noticing}

\author{
John Fass \\ Royal College of Art, \\ London, SW7 2EU \\ John.fass@gmail.com
}

\author{
Angus Main \\ Royal College of Art, \\ London, SW7 2EU \\ me@angusmain.com
}

\begin{abstract}
This paper describes an ongoing design project relating to online news and how alterations to news stories are hidden from the reader. As the delivery and consumption of news content online continues to overtake other channels in reader numbers and market penetration, so methods of transparency and reliability developed over centuries continue also to be tested by digital media. We have carried out content analysis on existing stories and examined how news organisations and channels handle rapidly evolving news stories. We have proceeded to develop low fidelity prototypes and an interaction model to test our design approach. The outcomes are in production and will result in a digital artifact that reveals editorial changes to news items. These changes will be made visible within the browser. The implications of the project relate to the wider question of news truth-telling, trust and online news credibility.
\end{abstract}

\section{Author Keywords}

Online news, interaction design, design methods, design processes.

\section{ACM Classification Keywords}

H.5.m. Information interfaces and presentation; J.7

Publishing; K.8.m Personal Computing.

\section{General Terms}

Human Factors; Experimentation; Human Factors.

\section{INTRODUCTION}

The collection, consumption and distribution of news content has been dramatically disrupted by technological developments and the digital world. This has had a significant impact on how the news is collected, where and how it is consumed and who writes the news [2]. Credibility of online news has emerged as a research topic, with some scholars [1] finding 'a growing public distrust of online sources of information' because of the perceived freedom of access it offers and the lack of scrutiny it demands from news authors. Although television news could be said to have ushered in the era of the 24 hour news cycle, microblogging services such as twitter, tumblr and Jaiku often mean traditional news organisations struggle to keep up with second-by-second news updates [14]. (The discovery and subsequent death of Osama Bin Laden in Pakistan in May 2011 is a recent example of this phenomenon [10]). In contrast Petrovic et. al. [14] have shown how Twitter adds to event coverage by including multiple voices but does not necessarily respond faster than traditional media in a breaking news scenario. There remain sufficient examples of Twitter beating mainstream media (for example; the discovery of ice on Mars which was sent via the mission's own Twitter account, or the liberation of kidnapped journalist Kosuke Tsuneoka who tweeted his own release) to the story to expect more research in this area.

With news stories updated in close-to-real time it is not at all uncommon for a single online news story to be presented in 4 or 5 different versions in the course of a single day. Newsdiffs [33], a website, finds and logs examples of these changes in the US media. Newsdiffs regularly identifies and highlights up to 20 changes to a single article over 12 hours. One limitation of Newsdiffs is that it contains no contextualising information.

These alterations in the face of rapidly changing facts are usually hidden from the reader. What changes were made? Why were changes made? Who made them? This paper describes an ongoing design project that attempts to reveal to readers when, by whom and why online news stories are changed.

\section{PRACTICE}

Apart from the mobile apps and websites of mainstream news organisations, practical work in the field of online news includes Summly a smartphone app that reduces news to easily digested 'algorithmically generated summaries using artificial intelligence and natural language processing' [39]. Another app Clipped [26] presents news as bullet points. Prismatic [24], Pulse [37], and SkyGrid [27] are all mobile aggregators that synthesise feeds from a 
wide range of news sources. Flipboard [23], Zite [44], and Feeddler RSS [13] are news presentation apps that allow users to pull in their own news sources from around the web. All the above apps are primarily designed to present news in digestible formats and are arranged around flexible grids where stories can be browsed and prioritised by the user. Propublica [35] is an independent news-gathering website that includes ChangeTracker [36], a plug-in launched in 2009 (it is no longer in development) that tracked changes to the official WhiteHouse.gov website. NewsDiffs [33], as mentioned above, provides details of changes to online news articles but does not show any contextualising information and is limited to CNN.com, nytimes.com, politico.com, washingtonpost.com, and bbc.co.uk. Politwoops [34] reveals deleted Tweets by politicians, and MediaBugs [29] provides an error reporting widget that enables readers to log any mistakes they encounter in online news text.

The News Inspector is conceived to provide a level of user experience not featured by any existing online project that engages with the ideas of news transparency, changes to online articles, or trackable online journalism.

There is increasing awareness of the need for transparency in reporting corrections to online news stories. The Knight Foundation [28], a private non-profit US foundation, supports a number of initiatives related to news transparency while the Media Standards Trust [30] runs the Transparency Initiative which 'looks at ways of making the provenance of news more transparent online, particularly through the use of metadata' [30]. A web project called hNews [31] is hosted by the Media Standards Trust. hNews was developed with the Associated Press as a news microformat which uses existing HTML/XHTML to report the metadata of online text. This enables parallel services such as itchanged, a Firefox browser extension which alerts readers of changes to articles they are tracking through hNews.

Scott Rosenberg [40], Arthur S. Brisbane [41], and Craig Silverman [42] have all written on the issue of institutional responses to what Rosenberg calls 'the mutability of online content'. They have highlighted cases of articles changing, disappearing, content removed, and articles rewritten. The News Inspector exists in the context of current thinking about news content and the associated examination of how easily and undetectably it is altered.

\section{MEDIA}

Printed news embodies an automatic sense of recency. The latest version of the story is the one in front of you. Tomorrow's edition will be updated to reflect any new facts that might emerge. It is straightforward to read the history of the story in previous printed editions. This sense of time is implicit in the medium and in the means of production (a new edition is printed every day).
News delivery is starting to respond in tangible ways to the increasingly rapid pace of digital media. The BBC, Guardian, Daily Mail and Financial Times websites all use a minute-by-minute blog format for certain stories, with posts in descending time order, all time stamped, arranged in an infinitely scrolling vertical column. The BBC reflects its moving image bias by embedding related video content, while The Guardian often includes quotes, comments, and third party material, such as tweets, in the blog timeline. Web based news rarely has the same implicit sequences or chronological cues of printed and television news.

As the production paradigms of both print news and television news continue to converge on web experiences, new hybrid forms and standards will be necessary to take account of; the speed of news gathering, network effects, authentication, and credibility. Editorial processes are already under strain from the extra resources needed to examine the internet for possible stories, with the BBC having a 20 -strong social media team authenticating social media content.

A news article no longer represents a snapshot in time, but is rather a continually corrected, living reflection of that news story. The clear chronology of the news is therefore disappearing, and it is harder to determine how a story unfolds, or how the facts have come to light. Editorial mistakes and wrong assumptions are removed, and an online news article can therefore tell you accurately what people are thinking now, but not what they are were thinking five minutes ago and why. Arguably, this makes online news more accurate, but the ability of news outlets to immediately rewrite the news, rather than making more explicit changes or retractions is to the detriment of clarity and honesty. The News Inspector shown here is intended to mitigate against this sense of invisible correction.

\section{PRESENTATION}

The same news story is commonly repurposed for multiple media channels within the same publisher i.e. print, tweet, web-streaming, SMS and online text versions. This has been identified as a problem for news journalists termed 'hamsterization' [13]. The requirements to deliver different versions of the same story for various media often comes at the expense of fact checking, long form writing and indepth investigation. How the news is presented affects how it is understood; there has been a marked convergence in visual news presentation across different media [6]. This has been characterised as a tendency towards easily consumed news bites as exemplified by Summly [36] and Clipped [26]. Screen-based news layouts are designed to take advantage of the speed of digital technology and to be rapidly scanned and skimmed by the reader. Layouts prioritise highly modular designs that can be ordered through screen menus and maximise use of valuable screen real estate. 
Online news is also rigidly hierarchical in its presentation, with space for only a limited number of words per story, per screen. Further detail, comment or contextualising information is hidden behind multiple navigation levels. It is a highly structured environment that some researchers have suggested leads to highly structured understandings and similarly structured memory recall [3].

Dominant interaction patterns for online news are limited to hyperlinking between articles, playing video content in embedded players and viewing slideshows of images. More participative interactive systems include commenting, and more in depth interactive reporting through montages of text and image. There is a relatively constrained palette of page designs and menu systems. The News Inspector takes advantage of metadata standards to deliver information about article changes. It is intended to promote reflection, to expose the meta-narrative at work in the story, and to shed light on how news-truth comes about.

\section{METHODS}

The News Inspector is designed to be a layer over the screen based news environment. It does not provide news, aggregate or filter news stories, it is intended to function like a magnifier on top of an online news story. It works like a widget or plug-in that addresses a preexisting information system. Early work on the project consisted of some diagrammatic prototypes of how the interface could look and what kind of interaction would best serve the project objectives. These diagrams do not feature highly detailed specifications and are intended as a means of visual thinking [15].

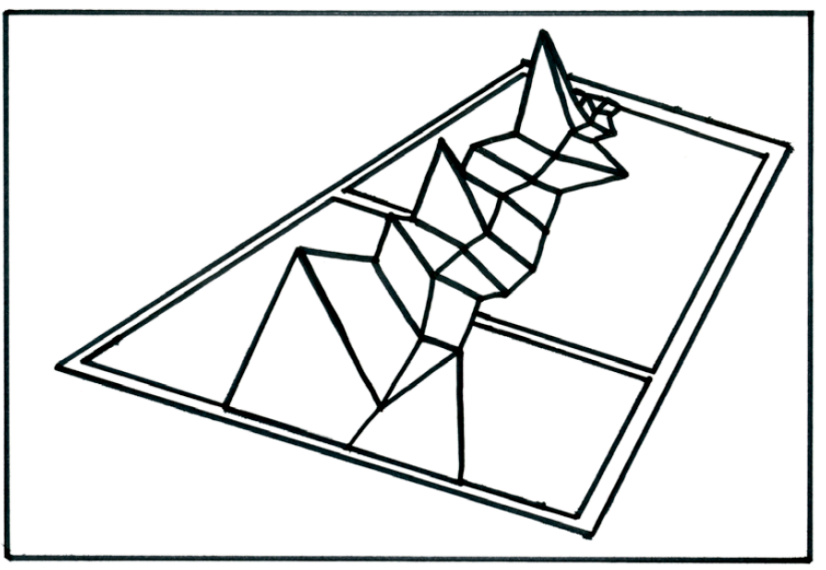

Figure 1; Prototype diagram

Paper prototypes allowed us to think about visual presentation and about how to address interaction. The website page paradigm is a consequence of 'print bias' in screen interactions and news outlets seem particularly prone to presenting their content as if it were laid out on printed pages. Most articles do not contain extensive hyperlinks in their body copy and often extend through different pages on the same screen. How can the article page be mined to reveal hidden content? Can we think of the page as a landscape of information and overlay the metadata? Could we navigate the alterations in a simulated three-dimensional datascape? What metaphors might be useful?

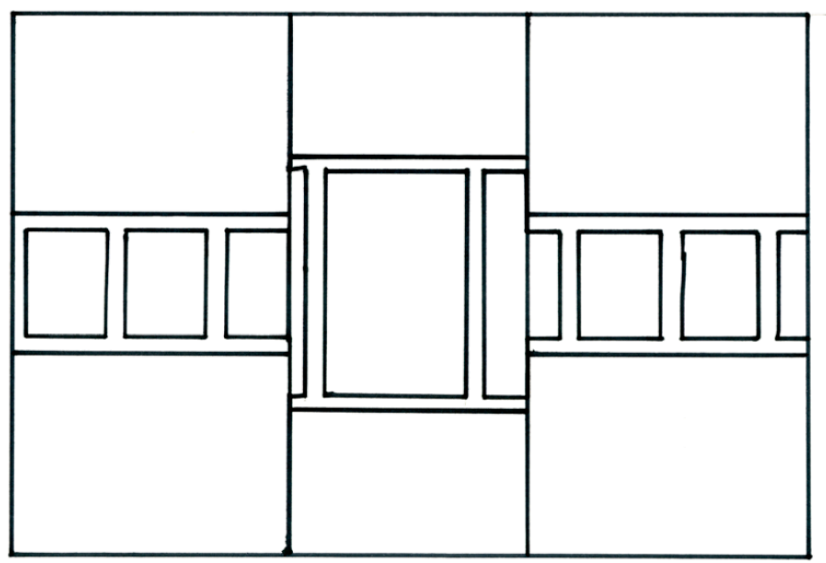

Figure 2; Prototype diagram

Paper prototyping as a design research method is a wellestablished approach to the development of digital products and has been used for desktop interface design [18], interaction design [2], usability studies [16], and mobile applications [5]. We have used paper as a medium to explore top-level interaction models and metaphors. Prototyping with paper is low cost, low fidelity, enables rapid iteration, and allowed us to communicate early stageideas using paper and pen. The paper prototypes did themselves evolve from rough sketches to the more structured visual examples shown above as ideas became formalised and the system gained resolution. There were distinct stages to the use of paper as a prototyping material:

\section{Stage 1. Quick and easy}

Freehand drawing with a graphite pencil on A4 layout paper pad. Sheets can be detached and placed in thematic or chronological sequence, paper is 50 gsm so transparent and suitable for layering, pencil is ubiquitous, erasable and durable. Stage 1 emphasises speed over accuracy, ease of use over compositional skill, and lack of precise control over structure. Results are easy to share, annotate, and transport.

\section{Stage 2 Linearity}

Rough sketches are synthesised into distinct ideas with common elements identified and placed in themes. A separate sheet is used to illustrate each idea. Materials are A4 cartridge paper, pencil, and ruler. Cartridge paper is $150 \mathrm{gsm}$ weight so opaque. The heavier paper weight also implies greater value and more care necessary. Sketches are outlined at screen ratio size using straight lines drawn with a ruler with a view to final materials. The process is much more controlled in stage 2, rectilinear sketches in pencil form a basis for more permanent lines to be drawn. 


\section{Stage 3 Gestalt}

Precise pencil diagrams are drawn over in permanent black felt tip pen. The pen affords no shading, varying line widths, or erasing, the same paper sheet as in stage 2 is used. Pencil lines are then erased leaving a black pen diagram with consistent $2 \mathrm{~mm}$ line widths. Stage 3 is the most controlled and precise, annotations are removed, the visual prototype takes its final form.

Future work could be to reinstate annotations that indicate interactions, relate the different drawings more directly to each other, and include system level information. This method of exploring visual ideas varies in some ways from software prototyping since we are not concerned at diagram stage with interaction details. They are more similar to diagrammatic conceptual illustrations than the paper prototypes commonly encountered in a software development process.

\section{ANALYSIS}

The diagrams led to a textual analysis of an online news story published on www.bbc.co.uk on May 2 2012. The article, which reports on court proceedings, was altered significantly over the course of 5 hours. Between 12.47 and 15.12 over $65 \%$ of the story was rewritten. The BBC does include an indication of online article updates at the top of the screen but only specifies when a report was updated, not what changes were made by whom or why. This method of direct comparison is facilitated by the visual design and layout of online news, which is presented in consistent formats (column width, type size, line length) as outlined above. We also compared multiple versions of the same article so discrepancies between iterations were easier to detect. We were not concerned at this stage with semantic changes in content but in solecistic identification. i.e. what appears 'wrong' (different) in version two when compared to version one. This method of textual analysis comprised a simple word count at first instance, a quantitative measure of text volume intended to determine a change in content size.

We have followed Krippendorf's [12] checklist for textual analysis:

\section{Which data are analysed?}

Two versions of the same news article, written in English, published online at www.bbc.co.uk.

\section{How are they defined?}

They are considered as limited to one news story with multiple iterations. Data is defined as the total of all the words in the article versions, including metadata where publicly displayed, system level information, and punctuation.

\section{What is the population from which they are drawn?}

The data population is digital news articles, published online, and publicly available.

\section{What is the context relative to which the data are analysed?}

The data are analysed relative to the context of online news truthfulness, online news credibility, online news production paradigms, and online news publishing channels.

\section{What are the boundaries of the analysis?}

The analysis is limited to two versions of one article, published on one particular date. The aim of the analysis is limited to detecting differences in content between the two versions.

\section{What is the target of the inferences?}

Inferences drawn from the analysis are intended to inform the design of a digital instrument whose purpose is to reveal unannounced changes to online news articles.

\section{PROCEDURE}

Changes were tracked initially through close online reading, pen and paper note taking and subsequent annotation of the data using coloured highlights over the text using two different colours; one for each version. Highlighted sections show observed differences between versions. These differences include: Word count, changes in the time and sequence of events, names, description of events and headlines. The analytical process confirmed our hypothesis that the article did show differences and they had been altered by persons unknown, for reasons unknown, at a time unknown. We have developed some initial visual expressions of these changes and how they might be communicated. Visual annotation of text documents has been widely used as qualitative data analysis in the context of literary criticism [8] and field biology [21] among others.

Further analytical research could include word frequency analysis [20], and category counts [20]. However, since our focus at this stage is less on the nature or semantic characteristics of editorial changes, and more on revealing that they have taken place, the current research has focused on designing an effective interactive mechanism to represent changes. 

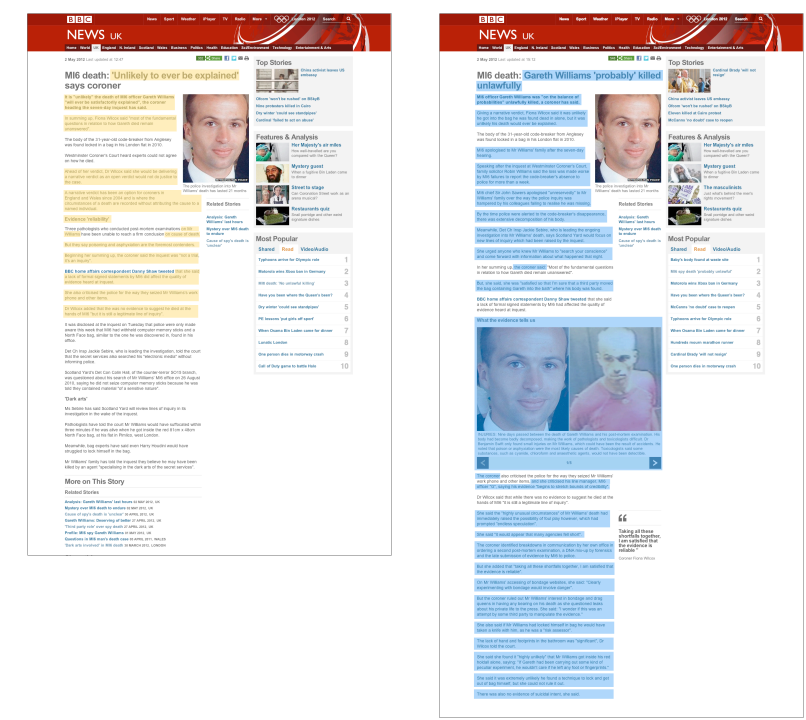

Figure 3; Article comparison.

The viewer can piece together the details of the changes only by printing out or saving the article every hour or so (perhaps even more frequently in a rapidly evolving news situation, such as the recent Utoya shootings incident in Norway July 22, 2011). By highlighting these changes visually with screenshots of the article, alterations become immediately visible. Using this method allowed the scale of changes and their exact nature (by direct side by side comparison) to emerge. While highlighting changes revealed the extent of alterations to one particular article, it does not represent a scalable finding and further research of this type is necessary.

Further analysis (see Fig. 4) was done diagrammatically by arranging versions of a story over some months on a vertical timeline. Although not focused on invisible changes to the same article but rather on iterations of a news story over time, this exercise brought the discussion of time and adjustable time indeces to the forefront of the design research process.

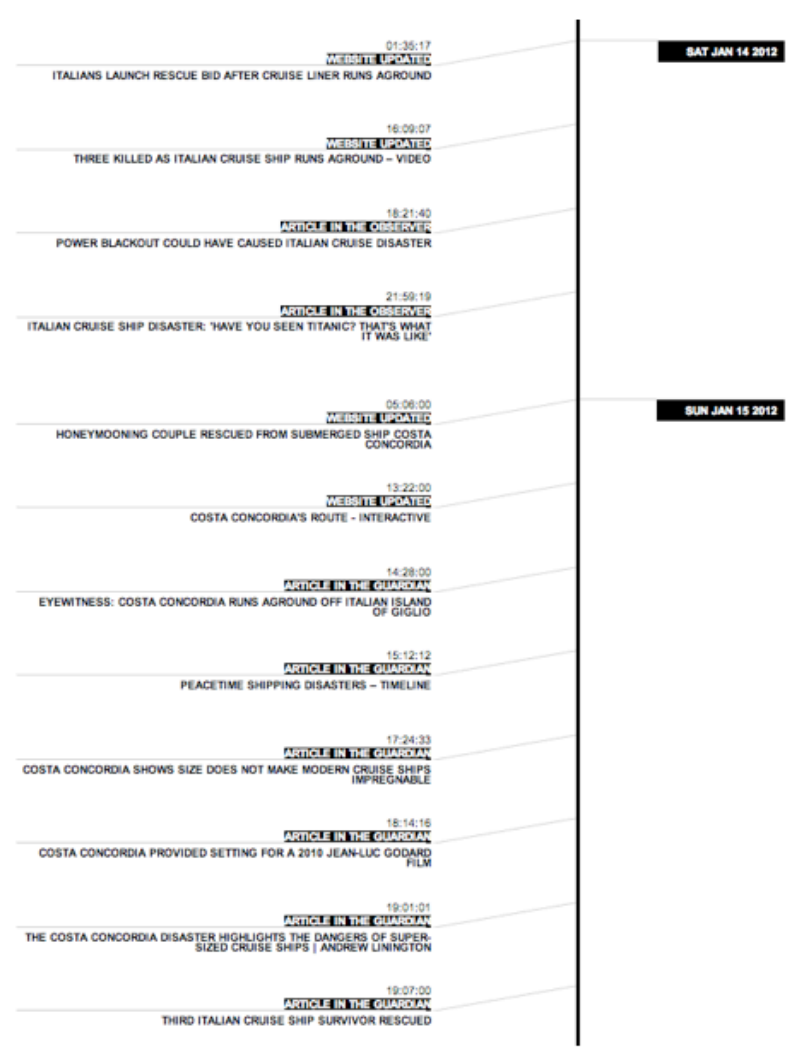

Figure 4; Story over time.

Tracking changes on the home page of a mainstream news site over 24 hours also showed us how articles are resized, retitled and repositioned over time to foreground stories the news outlet wishes to emphasise or respond to clickthroughs. This insight was specifically gained by using a script to produce an animation and brought the dimension of movement to the design process.

\section{CITIZEN ANALYSIS}

An active network of informal online news watchers regularly captures and posts screenshots of news websites featuring altered content. In a blog post published by The Electronic Intifada website [22] entitled: 'The Screenshots prove it: New York Times altered headline to remove words "Israeli Occupied" Ali Abunimah demonstrates how an online news article's headline was altered to reflect institutional attitudes to the Arab-Israeli conflict. 


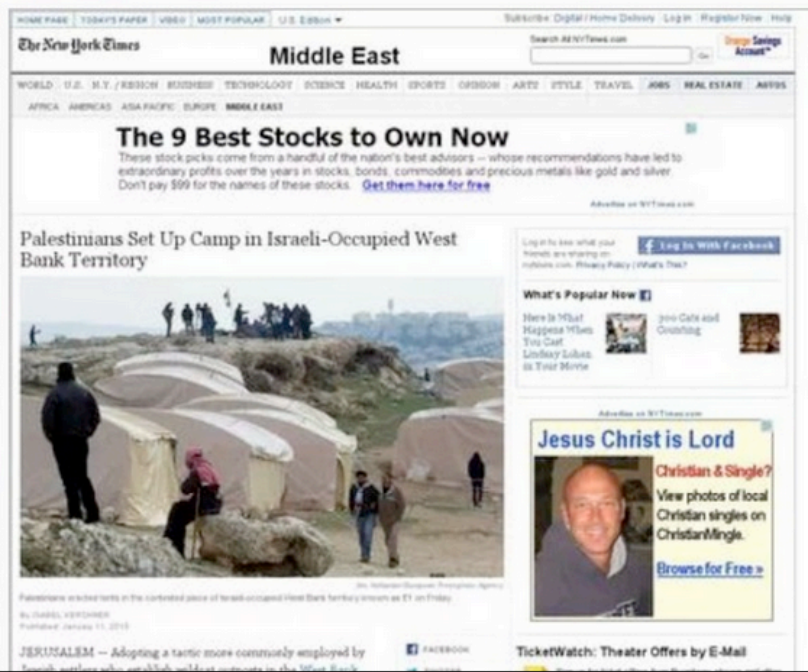

Figure 5. Screenshot from www.electronicintifada.net

Similarly blogger Danica Lo writing on Style Bistro [38] showed how an article published by WWD.com [43] was altered without notice to sanitise racially provocative comments.

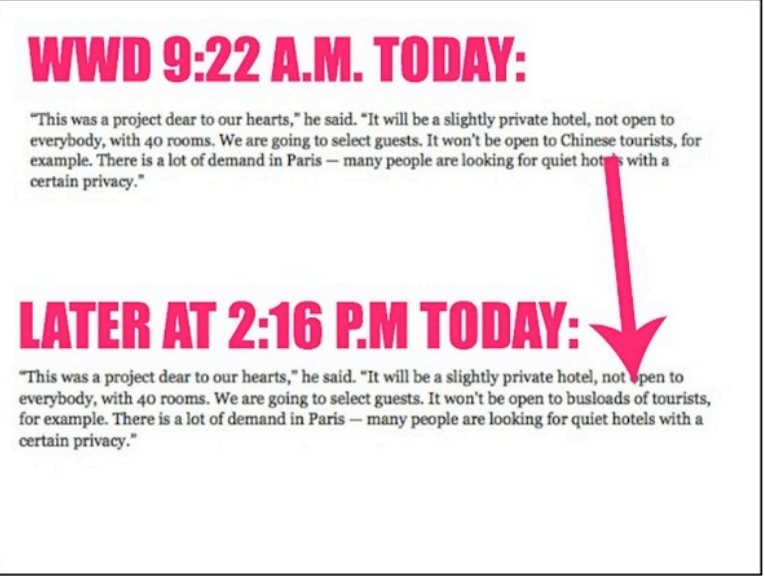

Figure 6. Screenshot from www.stylebistro.com

In a similar example the New Statesman's [32] Alex Hern points out the changes to an online article by the Daily Mail from 13 August 2012 that was 'mysteriously updated'. He includes a screenshot with commentary on visual aspects of the changes implemented and posits a social media led news process he terms "editing by Twitter" where news outlets monitor social media for reaction and adjust their content accordingly. Editorial decisions are therefore made in some cases on the basis of social media responses. This process would imply the use of Twitter specifically as a driver of mainstream news making.

\section{Update}

The Daily Mail is practicing its usual "editing by Twitter", it seems. The piece is a month old - originally published on July 13 - but has mysteriously been updated in the last few minutes to remove the offending paragraph.

Padraig Reidy managed to save a screenshot of the original piece (click for big):

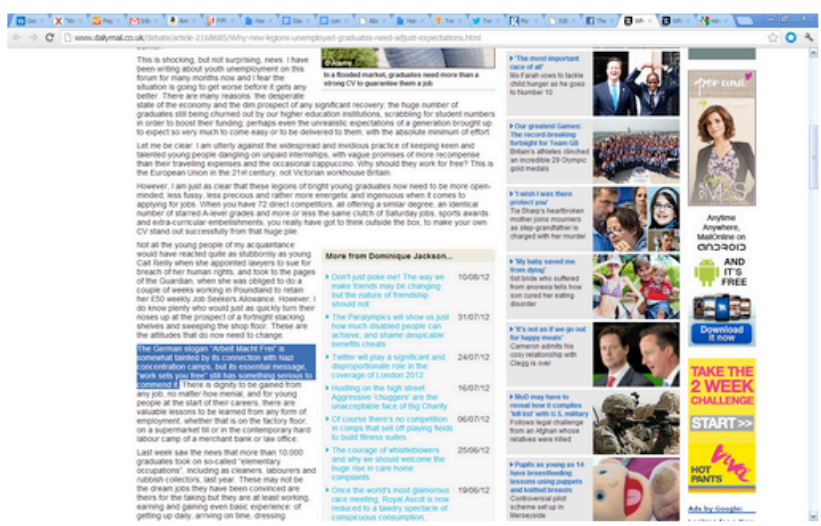

Hilariously, at least at the time of writing, the piece was so hastily edited that the font size in the new paragraphs is noticeably different from the old.

\section{Figure 7. Screenshot from www.newstatesman.com}

The three examples shown above feature some common elements: They are explicitly concerned with a moral dimension to online news changes rather than, for example, corrections to sports scores or updated recipes. They are all generated by bloggers rather than mainstream journalists and connect with meta-level concerns of online truth and credibility. They all feature screenshots which fulfill two important functions. Firstly, screenshots are visual records and show the surrounding context of the original articles, in some cases with brand banner clearly visible and 'screen furniture' such as scrollers, menus, and buttons also visible. Secondly, screenshots are in a more fixed format than hypertext pages, usually saved as .png or .bmp file formats and are perhaps considered more trustworthy.

\section{INTERACTION}

Online news articles exist in a carefully structured interactive environment, often evolved over many years. The screen real estate features many different options for rich interaction. The story shown in Figure 3 is placed within the pre existing visual framework and information structure of all $\mathrm{BBC}$ online news content, it contains over 75 separate immediately visible interactive elements. Including hidden menu items and sub navigation accessible with one click, this number rises to 145 . Interaction is sited on this page, (in the sense that the page has a unique URL), but it is also situated within the broader interactive ecology of $\mathrm{BBC}$ news content.

Because the News Inspector is intended to work across diverse sites, and therefore varied information structures, it demands a coherent interaction approach of its own, 
independent of the page it overlays. The challenge is to design a behavioural interactive texture with clearly indicated constraints and a distinct proprietary character. The purpose of the Inspector should be immediately apparent, the learning threshold low and cost of engagement minimal.

Constraints are a way of limiting the actions that can be performed on a system [4]. They help to enhance usability and reduce the probability of error. Psychological constraints include symbols, conventions and mapping [4]. In the case of the News Inspector, symbolic constraints are indicated by highlight colour, by textual labeling of functions and by implied tactility. Conventions are exploited by using the familiar metaphors of looking through a window at an external subject and being able to manipulate that window, (open, close, adjust). Finally, mapping is indicated by proximity (the magnifier reveals the details of the article that lies directly beneath it), and by making different parts of the underlying article visible as the magnifier scrolls over it.

When a system has a low learning threshold it is easy to work out what it does and how it does it. What actions are possible? How difficult are they to perform? The threshold can be lowered; by reducing depth of interaction, by minimizing or eliminating navigation and menus, and by providing useful default settings. The News Inspector, once launched, does not need to be activated, it moves in one axis only and has multiple input redundancies.

Cost of engagement refers to the level of intrusion into the online news experience the magnifier causes. The system should be easy to add and remove to the news page, there should be a minimal or zero disruption to the reading process and it should respond instantly to user input. These qualities notwithstanding, the News Inspector does deliberately set out to interrupt the reading of online news. It enforces a certain reflective distance by causing the expected layout and appearance to be filtered through an 'alterations filter'. This way of estranging the content from its context is an example of defamiliarisation or ostranenie [7], an established postmodernist strategy for revealing new meanings.

\section{REPRESENTATION}

Recent design directions for the News Inspector have borrowed from existing examples of how digital files are inspected in fine detail. This commonly consists of a zoom function or overlaying magnifying device (see Fig. 8).

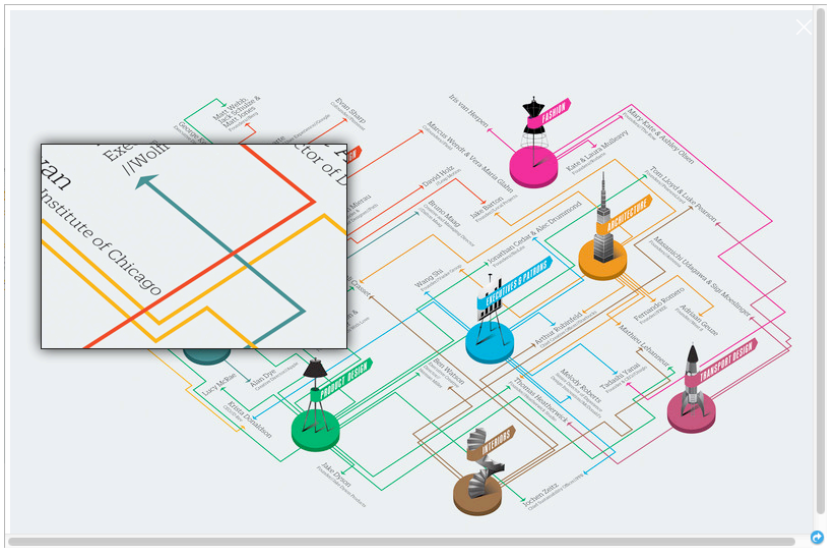

Figure 8. www.fastcodesign.com

In the context of online news, time can be relative to publication date, the reported sequence of events in the article or the longer timescale of the story over some months or years. How these different conceptions of time are communicated remains a challenge for the online environment. While a printed paper can be archived and navigated according to the date at the top of the page, blog posts are time stamped automatically at system level with accuracy depending on system configuration. News credibility can depend on a number of factors; including system security and administrative access.

Other design considerations include dimensionality. We have explored Systems such as Holobox (see Fig. 9) to think about the angles of the story as a direct design analogy and whether we can build an awareness of dimensionality into the News Inspector.

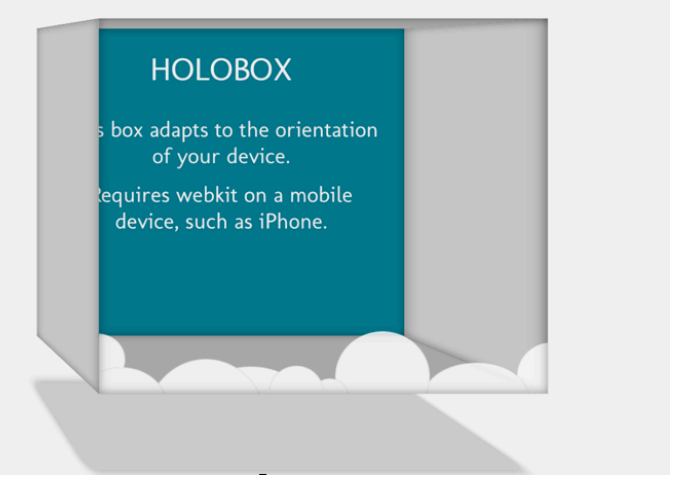

Figure 9. www.hakim.se

By tilting the screen of a handheld device such as a smartphone or tablet, contextual information could appear. This would lend a directly physical or embodied aspect to the interaction with different levels of information shown as tilt angle is increased. The design challenge of this approach lies in integrating the News Inspector with existing systems and the page layout of mainstream news websites. 
Current design directions incorporate a timeline scrubber visually connected to highlighting of updated or altered text (see Fig. 10). As the user drags a pointer up and down a timeline of the story, different parts of the relevant article are highlighted to indicate changes. More in-depth information, such as the name of the editor who made the changes, and why they were made could be delivered in a side bar, roll over or floating pop up.

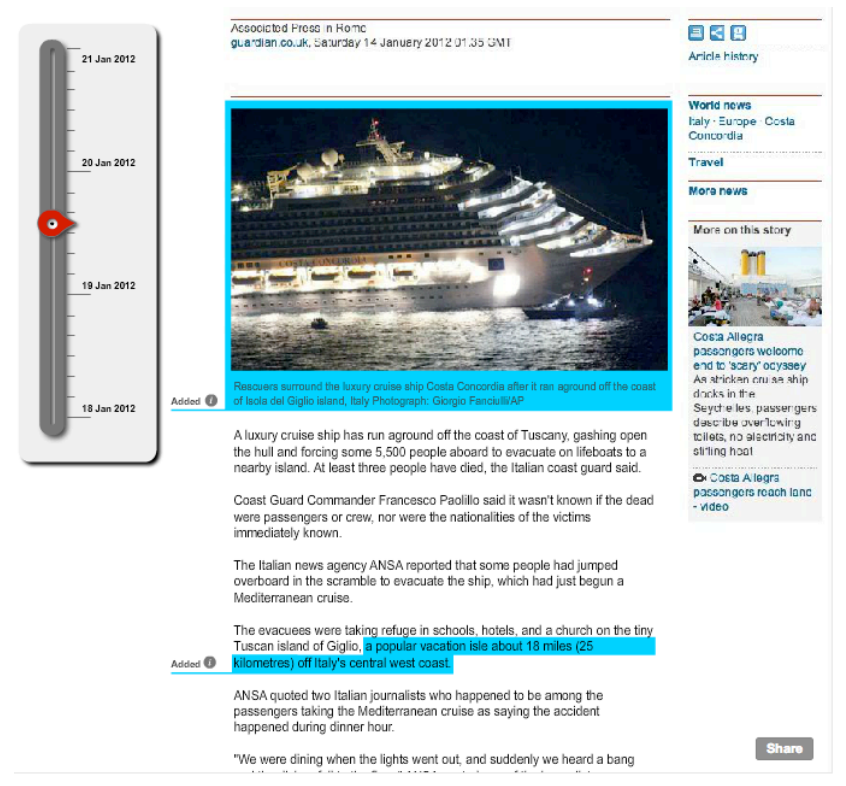

Figure 10. News Inspector

\section{CONCLUSION}

This paper has described the broad context of the project, some of the concerns relating to online news and the institutional and production environment it depends on. We have examined how online news embodies a specific view of time and recency, and how presentation influences understanding. A data collection and analysis method is outlined with examples from citizen engagement. Design research methods are used, specifically paper prototyping and digital design iterations. We have explored visual thinking as a tool for design development and analysis while showing how it evolves over time. Some examples have been given explaining both existing systems and showing how we have arrived at the present version of the project. We have made some initial suggestions for how to design for interaction in this context. The News Inspector is a work in progress and the design process continues to take account of all these factors as the project develops. This paper should be seen as a design case in development that engages with various strands of thought within HCI.

\section{REFERENCES}

1. Abdulla, R. A., Casey, D., Driscoll, P., Garrison, B., Salwen, M., The Credibility of Newspapers, Television News and Online News, Association for Education in Journalism and Mass Communication, Miami, Fla., 2002.

2. Baptista, A., Pereira, T. The Omnipaper metadata RDF/XML prototype implementation, Universidade do Minho, 2003.

3. Boczkowski, P. J., Mitchelstein, E., Between Tradition and change: A review of recent research on online news production, Journalism 10: 562 , Sage Publications, (2009).

4. Butler, J., Holden, K., Lidwell, W. Universal Principles of Design . Rockport Publishers Inc. (2003).

5. Carriço L., de Sá, M., Low-fi prototyping for mobile devices. Proc. CHI '06 Extended Abstracts on Human Factors in Computing Systems (CHI EA '06). ACM, New York, NY, USA, 694-699.

6. Cooke, L., A visual convergence of print, television, and the internet: charting 40 years of design change in news presentation. New Media and Society Vol7 (1):22-46 Sage Publications (2005).

7. Crawford, L. Victor Schklovskij: Différence in Defamiliarisation, Comparative Literature. Vol. 36 No. 3. University of Oregon (1984).

8. Denzin, N. K., Lincoln, Y. S., Handbook of Qualitative Research, Sage Publications Inc, 2000.

10. Feldman, C. S., Rosenberg, H., No Time to Think, The Continuum International Publishing Group Inc., (2008)

11. Juristo, N., Windl, H., Constantine, L. Usability basics for software developers. Software, IEEE Vol.18. Issue 1.45

12. Krippendorf, K, Content Analysis: an introduction to its methodology, Sage Publications Inc. 2012.

13. Lasar, M., Has the Internet 'Hamsterized' Journalism? http://arstechnica.com/business/2011/06/hastheinternet- hamsterized-journalism/ (2011)

14. Macdonald, C., McCreadie, R., Osborne, M., Ounis, I., Petrovic, S. Shrimpton, L., Can Twitter replace Newswire for breaking news? Assoc. for 
the Advancement of Artificial Intelligence, 2013.

15. McKim, R. H., Experiences in Visual Thinking, Brooks/Cole Publishing Company (1972).

16. Norrie, M. C., Signer, B., PaperPoint: a paperbased presentation and interactive paper prototyping tool. Proc. 1st international conference on Tangible and embedded interaction (TEI '07). ACM, New York, NY, USA, 57-64.

17. Rennison, E., Galaxy of News, An Approach to Visualizing and Understanding Expansive News Landscapes (1994). MIT Media Lab, Proc. UIST '94, the 7th Annual ACM Symposium on User Interface and Technology.

18. Snyder, C., Paper Prototyping, Elsevier, 2003.

19. Thurman, N., J., Forums for Citizen Journalists? Adoption of User Generated Content Initiatives by Online Media. New Media and Society 10(1), Sage Publications Ltd. (2008).

20. Weber, R. P., Basic Content Analysis, Sage Publications Inc. 1990.

21. Yeh, R., Liao, C., Klemmer, S., Guimbretière, F., Lee, B., Kakaradov, B., Stamberger, J., Paepcke, A. ButterflyNet: a mobile capture and access system for field biology research. Proc. SIGCHI Conference on Human Factors in Computing Systems (CHI '06), ACM, New York, NY, USA, 571-580.

22. http://electronicintifada.net/blogs/aliabunimah/screenshots-prove-it-new-york-timesaltered-headline-remove-words-israeli, accessed 26/07/2013.

23. https://flipboard.com/, accessed 23/07/2013

24. http://getprismatic.com/, accessed 23/07/2012

25. https://itunes.apple.com/au/app/feeddler-rssreader-pro/id365710282? $\mathrm{mt}=8$, accessed 23/07/2013

26. https://itunes.apple.com/gb/app/id583616193?mt= 8\&affId=1736887, accessed 23/07/2013.

27. https://itunes.apple.com/gb/app/skygrid/id3641879
$29 ? \mathrm{mt}=8$, accessed 23/07/2013.

28. http://www.knightfoundation.org/pressroom/press-release/open-government-projectsreceive-more-32-million-w/, accessed 23/07/2013.

29. http://mediabugs.org/pages/widget, accessed 23/07/2013.

30. http://mediastandardstrust.org/projects/transparenc y-initiative/, accessed 23/07/2013.

31. http://microformats.org/wiki/hnews, accessed 23/07/2013.

32. http://www.newstatesman.com/blogs/media/2012/ 08/mail-online-unemployed-graduates-arbeitmacht-frei , accessed 29/07/2013.

33. http://newsdiffs.org/examples/, accessed 22/07/13.

34. http://politwoops.sunlightfoundation.com/, accessed 23/07/2013.

35. http://www.propublica.org/ion/changetracker, accessed, 23/07/2013.

36. http://www.propublica.org/ion/changetracker, accessed 23/07/2013.

37. https://www.pulse.me/about/, accessed 23/07/2013.

38. http://www.stylebistro.com/Fashion+News/articles /6FMAdMrqW/Screenshot+WWD+Alter+Quote+ Protect+Zadig+Voltaire, accessed 28/07/2013

39. http://summly.com/index.html, accessed 23/07/2013.

40. http://www.wordyard.com/?s=politico, accessed 23/07/2013.

41. http://www.nytimes.com/2012/07/01/opinion/sund ay/article-changes-are-shown-in-a-tool-created-byoutsiders.html, accessed 31/07/2013.

42. http://www.poynter.org/author/craigsilverman/

43. http://www.wwd.com/, accessed 28/07/2013

44. http://www.zite.com/, accessed 23/07/2013 